\title{
Historical Ornamentation of Chinese Scroll Painting and Bengal Pata Painting
}

\author{
Rajiv Mandal ${ }^{1, *}$, Yang Xianyi ${ }^{1}$, Wang Meiyan ${ }^{1}$ \\ ${ }^{1}$ School of Art \& Design, Wuhan University of Technology, Wuhan, Hubei, China, 430070. \\ *Corespinding Author. Email: rajivmandal9@gmail.com
}

\begin{abstract}
History of Chinese scroll painting and Bengal pata painting as well as Kalighat pata painting is very old and vide. Mainly the scroll paintings carrying different stories and episodes of different Epics, Mythological stories, activities with landscapes and daily life ornamentations. This paper is carrying the historical description of Scroll paintings from Far East and India. Chinese scroll paintings reflect stories and activities with landscapes, flowers, birds, poems and the massages were the Chinese characters played an important role as well. The Chinese scroll painting is an important source to the linage of the traditional painting to modern. It depicts from court to individual memorable events and stories. Bengal pata paintings developed to reflect a variety of themes of Myth and the other historical events. The artists depict Hindu Gods, Goddesses and other mythological characters and their stories as the episodes from Vedas, Puranas and Mangal Kavyas. Bengal scroll also reflects the history as well as the social and cultural daily life activities; at the time of colonial period especially in Kalighat pata painting.
\end{abstract}

Keywords: Ornamentation, Chinese Scroll Painting, Landscapes and Daily Life Activities, Bengal Pata Painting, Mythical Stories, Chitrakar, Patuas, Kalighat Pata Painting.

\section{Historical Background}

A significant difference between Eastern and Western painting lies in the format. Unlike Western paintings, which are hung on walls and continuously visible to the eye, most Chinese paintings are not meant to be on constant view but are brought out to be seen only from time to time. This occasional viewing has everything to do with format. A predominant format of Chinese painting is the hand scroll, a continuous roll of paper or silk of varying length on which an image has been painted, and which, when not being viewed, remains rolled up.

Chinese scroll painting, art forms are practiced primarily in East Asia. The two dominant types may be illustrated by the Chinese landscape scroll, which is that culture's greatest contribution to the history of painting, and the Japanese narrative scroll, which developed the storytelling potential of painting. The earliest "illustrative" Chinese scrolls, forerunners of the narrative type, date from the late 4 th century $\mathrm{AD}$ and teach Buddhist moral lessons. The continuous scroll form was fully developed by the 7 th century. Such a scroll is opened from right to left and viewed on a table. The landscape hand scroll (makimono), a pictorial rather than narrative form, reached its greatest period in the 1oth and 11th centuries with masters such as Xu Daoning and Fan Kuan. The viewer becomes a traveller in these paintings, which offer the experience of moving through space

(C) AesthetixMS 2018. This Open Access article is published under a Creative Commons Attribution Non-Commercial 4.0 International License (http://creativecommons.org/licenses/by-nc/4.0/), which permits non-commercial re-use, distribution, and reproduction in any medium, provided the original work is properly cited. For citation use the DOI. For commercial re-use, please contact editor@chitrolekha.com 
and time. There is frequent depiction of roads or paths that seem to lead the viewer's eye into the work.

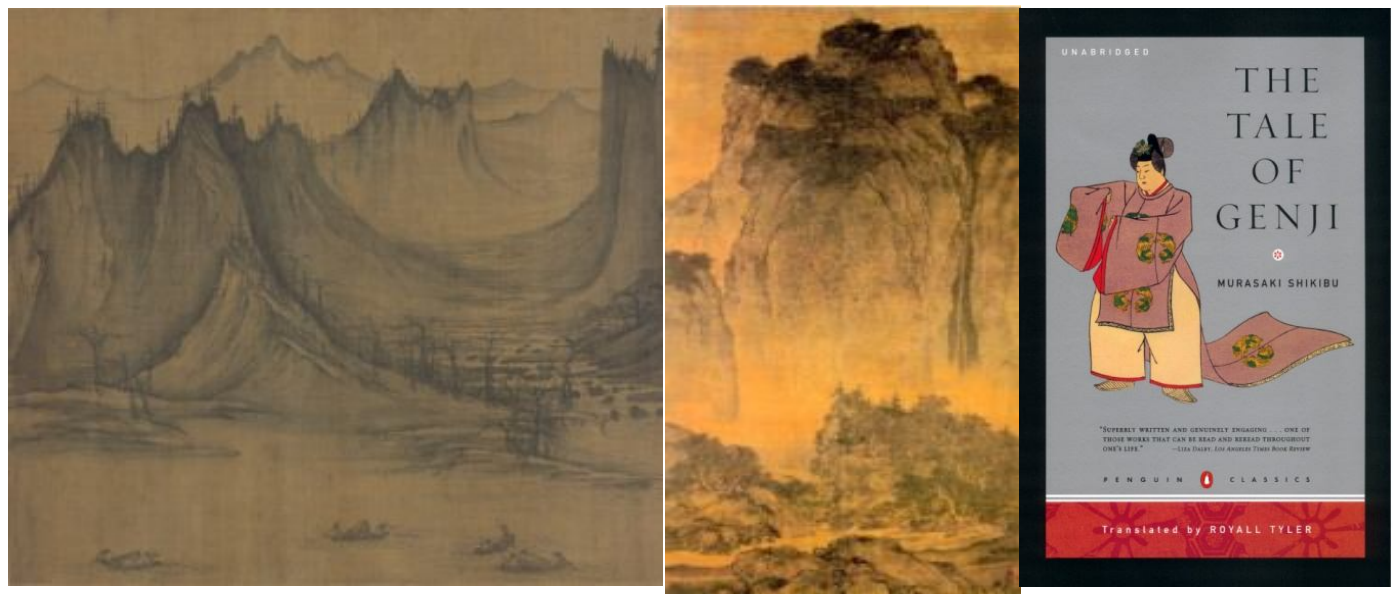

1. Artist Xu Daoning, Fishermen's Evening Song. 2. Artist Fan Kuan, Travellers Amid Mountains and Streams. 3. Author Murasaki Shikibu, Book The Tale of Genji.

Only about 2 feet (o.6 metre) of such a scroll should be viewed at one time or the spirit of the work is violated. One problem faced by the artists was a need for multiple vanishing points in generating a sense of perspective, since the imaginary viewer was assumed not to be stationary. They solved this in a variety of ways, causing one perspective point to fade unnoticed into the next. Nearly contemporary with the Chinese panoramic landscapes are the Japanese emakimono, scroll paintings of the 12th and 13th centuries. These are long horizontal scrolls, 10-15 inches (25$38 \mathrm{~cm}$ ) wide and up to 30 feet (9 metres) long. This painting tradition is called Yamato-e, or Japanese painting, to distinguish it from Japanese work in the Chinese manner. In the earliest example of this form, The Tale of Genji, Japan's great literary masterpiece, is shown in pictures alternating with text. Eventually the illustration in such works stood nearly alone, and typical subjects were the stories and biographies popular during Japan's Middle Ages. The Japanese taste for sensation and drama finds vivid expression in these scrolls. The buildings pictured in them are frequently without roofs, so that intimate interior scenes can be shown, and backgrounds are tilted forward so as to pack more incidents into a smaller space.

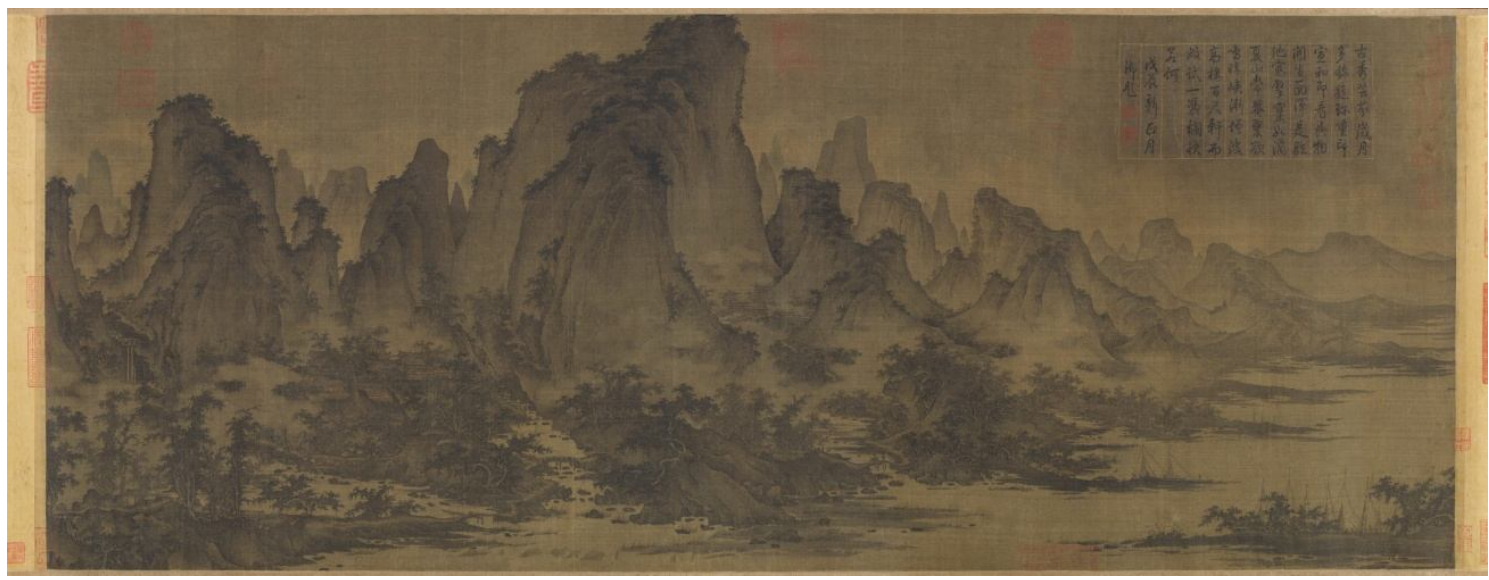

4. Artist: Attributed to Qu Ding (Chinese, active ca. 1023-ca. 1056), Northern Song dynasty (960-1127) Date: ca. 1050, Summer Mountains, Medium: Handscroll; ink and color on silk, Dimensions: Image: $177 / 8 \times 453 / 8 \mathrm{in}$. $(45.4 \times 115.3 \mathrm{~cm})$ Overall with mounting: 18 1/4 in. $\times 23 \mathrm{ft} .2$ in. $(46.4 \times 706.1 \mathrm{~cm})$, Credit Line: Ex coll.: C. C. Wang Family, Gift of The Dillon Fund, 1973 
During the renaissance of Chinese tradition that followed this period, an alcove intended for a picture or flower arrangement, the tokonoma, was introduced. Paintings were made vertical instead of horizontal in order to fit this space. These hanging kakemono, with their static compositions and contemplative themes, are more in the nature of Western paintings.

Simultaneously in Bengal, India. The word "pata" is derived from the Sanskrit word patta which means "a piece of cloth". Pata or "pot" as pronounced in Bengali means a woven surface, a paper or wooden panel on which painting is done. The artists who do this kind of works are popularly known as patuas; but they are also known as chitrakars, which literary means picture makers. It is interesting to note that the term has been adopted as a surname or a cast title. The term "patua" and "chitrakar" are used interchangeably, though the artists generally use the "chitrakar" as their surname. Traditionally patuas were men, who were assisted by their womenfolk in several stages; but in recent time women have also come forward to lay their claim as pata artists. These itinerant painters are part of a long lineage that has passed the tradition down for generations. In the past, patuas traveled long distance to perform in small villages, singing the songs and unrolling the scrolls panel by panel to accompany the narrative in exchange for food, clothing or payment. Now, many patuas perform in more populated areas for people who come to them to purchase their painted scrolls. But the artists are still struggling and trying to fulfilling their wishes or in other way trying to keep alive the age old art against every modernizing influence of the society.

The exact date of beginning the activities of the patuas at Kalighat is difficult to trace as there are no historical documents about the origin. Mainly pata originated in the late $18^{\text {th }}$ and the early $19^{\text {th }}$ century in Bengal, in the vicinity of Kalighat Kali Temple at Kolkata, West Bengal, from being items of souvenir taken by the visitors to the kali temple, the paintings over a period of time developed as a distinct school of Indian painting, kalighat. Pata painting grew so popular form of art in past that these were replicated by the institutions and Govt. of around the world. From the depiction of Hindu Gods, Goddesses and other mythological characters, the Kalighat pata paintings developed to reflects a variety of themes. Their paintings depicting different professions and customs were also popular even contemporary events like were the subject of many pata paintings. The artists also choose to portray secular themes and personalities and in the process played in the Independence movement as well.

By the early $19^{\text {th }}$ century the Kalighat Temple was a popular destination for local people, pilgrims and certain foreign visitors as well. With the rise of popularity and fame of the goddess Kali, many of the artisans and craftsmen flocked to Kalighat area to capitalise the new market by selling cheap religious souvenirs to the visitors. Soon after that a number of skilled artists moved to Kolkata from the rural Bengal especially from 24 Paraganas and Midnapore, West Bengal and set up stalls outside the Temple. In the villages they had painted long narrative stories on scrolls of handmade paper often stretched to over 25 feet in length and were known as patachitra. Each section was known as a pat and the artists therefore became known as patuas. The patuas would travel from village to village, unrolling the scroll a section at a time and singing the stories to their audiences. However, the visitors to Kalighat did not want to buy long scrolls which would take a lot of time to paint. The patuas therefore started painting single pictures involving just one or two figures that could be painted quickly with simple forms leaving the background plain and eliminating non- essential details. 


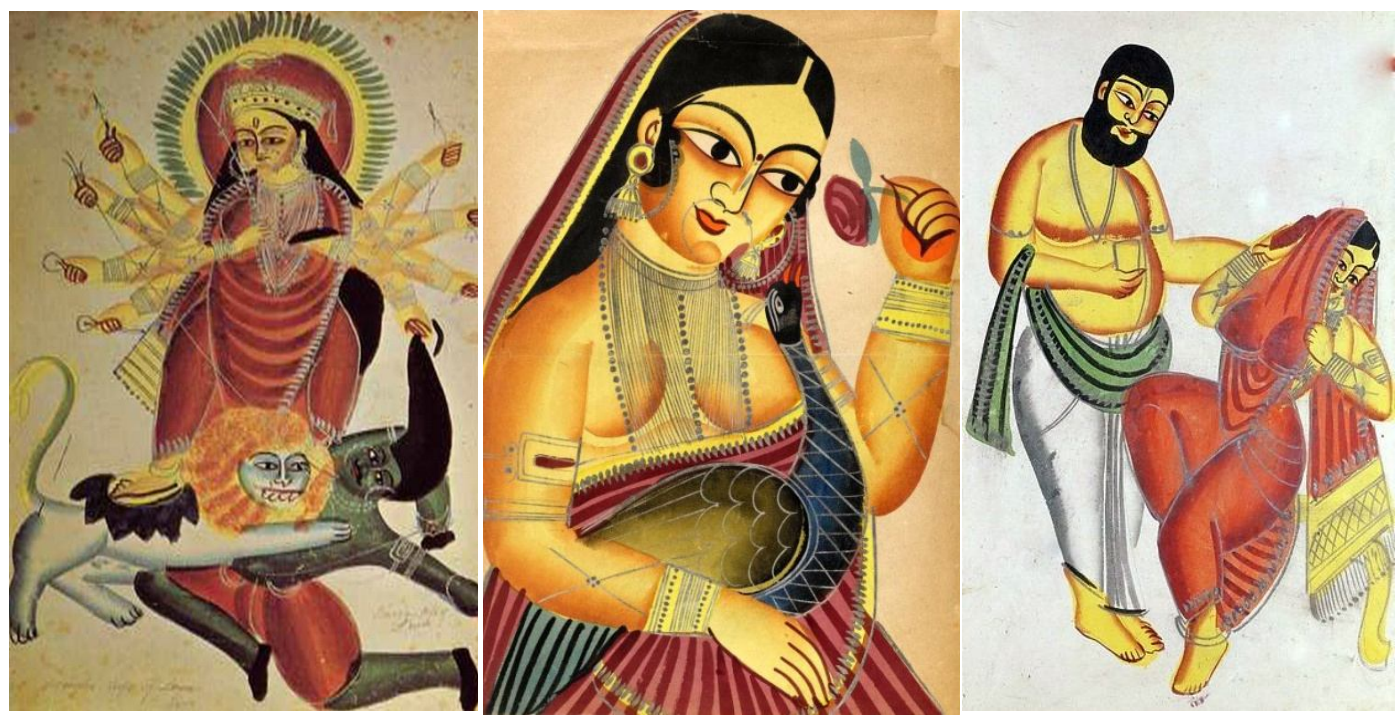

5. Kalighat Pata Scroll Painting, Hindu Goddess Durga killing the demon called "Mahisasur", CourtesyPrivate collection. 6. Kalighat Pata Scroll Painting, Bengali Indian Lady with a Peacock, CourtesyBrooklyn Museum, New York. 7. Kalighat Pata Scroll Painting, Mahant offers Ekoshi a Child Birth Medicine. Courtesy- Brooklyn Museum, New York.

\section{Ornamentation}

There is a long history in all over the world about scroll paintings, having to do with things that are written and then rolled up for easy transport and for ease in unrolling, either to view or to read. These rolled writings span the gamut from ancient biblical texts, from commendations and royal appointments, even for the simplest messages. But that's not what we mainly think of when we think of scrolls. When we think of scrolls, we might think of paintings we have seen produced in China or Japan hanging in a museum or hanging in a shrine. Most scrolls have a vertical orientation whether produced in China or Japan, were painted on paper or on silk; then glued to a backing, with a water soluble glue and then mounted with borders; these with a wood dowel at what constitutes the bottom of the scroll and with a thin piece of wood at the top of the scroll and with a silk or cotton ribbon or string to tie it tight when rolled up. Now, of course, most scrolls also had scroll ends at the bottom. These could be very simple wood or very elaborate in porcelain, or silver, or enamel, etc. The purpose of the wood dowel and the scroll ends is to provide weight so that, when the scroll was unrolled and hanging, it would lay flat and the painting could be easily viewed. The upper piece of wood served the same purpose but was thin so as to make a neat package when the scroll was rolled up and tied.

The paintings can be executed simply in ink only, or they can involve complex and minutely detailed highly colorful designs, which in both Chinese and Japanese scrolls, could include calligraphy, mythological subjects, historical subjects, figures, animals and more. They are also often religious in connotation, including Buddhist, Daoist, Shinto and others; which would involve deities, attendants and scenes. In China, as well as Korea, many scrolls were Ancestral portraits honoring relatives and court figures. In Tibet and Nepal, as well as China, Japan and India, there were religious scrolls, some of which were called Tankah and painted on cloth featuring various deities. As an aside, we should mention that there are also horizontal scrolls. These are generally referred to as 'hand' scrolls. They very often include calligraphy text or poems. They are sometimes commendations or appointments from the royal court and sometimes they are just very long continuous scenes. These scenes could be figural, mythological, birds and 
flowers, animals, etc and they generally roll out from 6 or 8 feet to as much as 20 feet long. There are some examples of Chinese scroll Paintings.

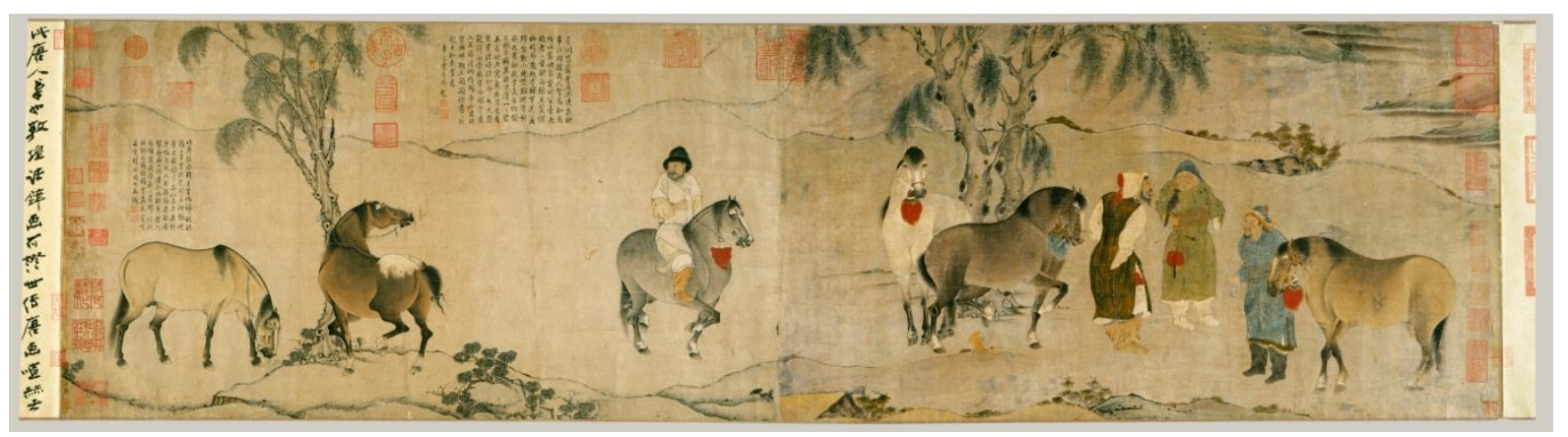

8. Artist: Unidentified Artists Chinese, 13th c. (1st half scroll); 14th c. (2nd half), Date: 13th-14th century, Six Horses, Medium: Handscroll; ink and color on paper, Dimensions: Image: 18 3/16 x 66 1/4 in. (46.2 x 168.3 cm), Overall with mounting: 18 9/16 x 254 3/4 in. (47.1 x 647.1 cm), Credit Line: Bequest of John M. Crawford Jr., 1988

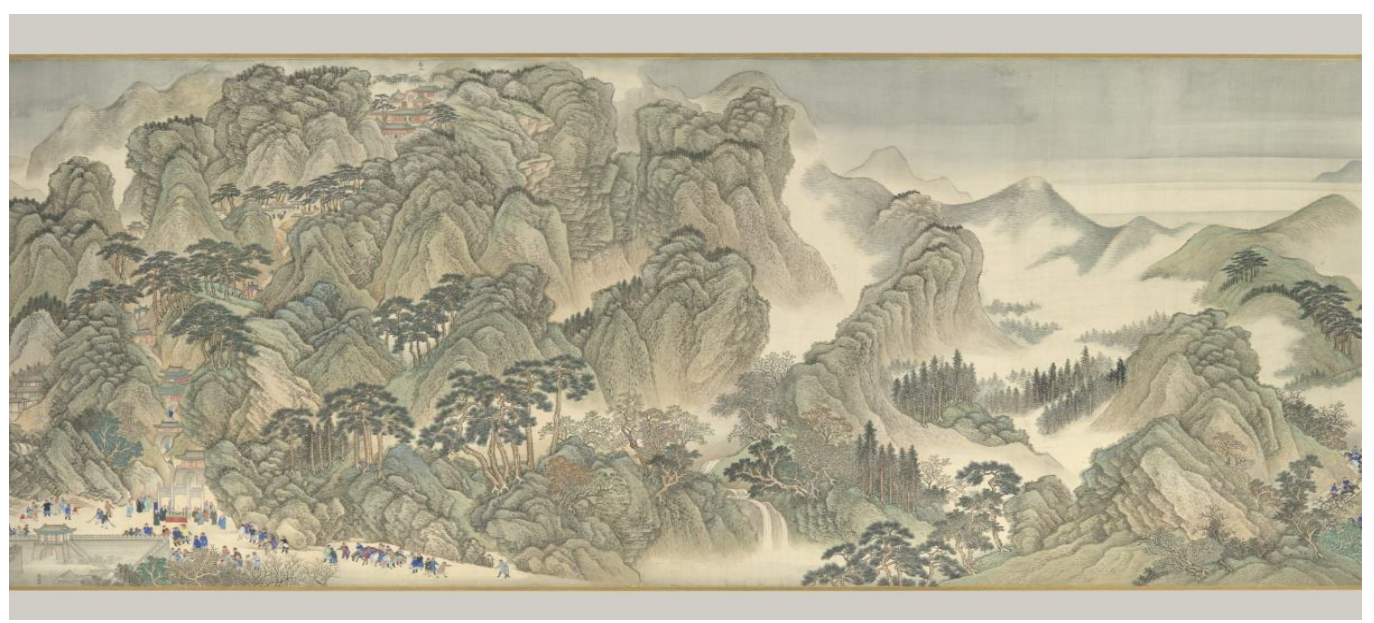

9. Artist: Wang Hui (Chinese, 1632-1717) and assistants, Period: Qing dynasty (1644-1911), Date: datable to 1698, The Kangxi Emperor's Southern Inspection Tour, Scroll Three: Ji'nan to Mount Tai, Medium: Handscroll; ink and color on silk, Dimensions: Image: $263 / 4$ in. $x 45 \mathrm{ft} .83 / 4$ in. $(67.9 \times 1393.8 \mathrm{~cm})$, Credit, Line: Purchase,

The Dillon Fund Gift, 1979.

The disparities in paper, pigment, and style between the two halves of this painting make it clear that they are by different hands and from different periods. In the first half of the painting, the horses and figures are well drawn and there is a rough vigor in the depiction of the landscape and trees. The shading of the land forms and the bold modulated outlines defining the figures, who wear typical Khitan costumes, most closely resemble murals done in the eleventh and twelfth centuries in north China, then ruled by the Khitan Liao dynasty (907-1125). In the second half, the unmodulated, "iron-wire" lines used to describe the drapery folds of the rider, the heavy outline of the rock, and the dry calligraphic texture of the tree suggest a fourteenth-century date. (See fig. 8)

In 1689 the Kangxi emperor (r. 1662-1722), a Manchu whose forebears had conquered China in 1644, made a grand tour to consolidate his authority over southern China. The renowned landscapist Wang Hui was commissioned to record the journey in a series of twelve oversize handscrolls. This scroll, the third in the set, highlights the emperor's visit to Mount Tai, China's "Sacred Peak of the East." Although Wang based his design on maps and woodblock prints - he never visited the mountain - he also connected specific sites with imaginary landscape passages 
inspired by classical precedents and employed a traditional "blue-and-green" palette to underscore the emperor's beneficent rule. (See fig. 9)

In Bengal, as I said earlier a traditional caste community of artist called patuas. Patuas like kumars started out in the village traditions as painters of scrolls or patas telling the popular mangal stories of the god and goddesses. For generations the scroll painters or patuas have gone village to village with their scrolls or pat singing stories in return for money or food. Many come from the Midnapur districts of West Bengal or else from 24 Parganas and Birbhum districts, also included Purulia, West Bengal and themselves chitrakar. The patas or scrolls are made of sheets of paper of equal or different sizes which are sown together. Originally they would have been painter on cloth and used to tell the religious stories such as the medieval mangal poem. Kalighat paintings were mainly sold as items of religious souvenir taken by the visitors to the Kali temple. It was thus obvious that the prime focus were given on religious and mythological characters.

From the depiction of Hindu gods \& goddesses, episodes from Ramayana and Mahabharata, scenes from the life of Lord Krishna to the other mythological characters, the Kalighat paintings developed to reflect a variety of religious themes. Amongst the deities, Kali (Goddess of power and destruction) was the favourite which was quite reasonable and apart from that Shiva (God of power and destruction) in the form of Panchanan or sitting along with Parvati (Shiva's wife) on Nandi (Shiva's Vahana) or carrying Sati, Lakshmi (Goddess of Money) herself or in the form of Gajalakshmi or Chandi as Kamalekamini, Durga as Mahishasur mardini, and other gods and goddesses like Kartikeya, Ganesha, Saraswati, Jagadhatri etc all were the popular themes of Kalighat paintings. Different incarnations of Vishnu like Parashurama, Balarama, Krishna, Rama etc. and series of scenes from life of Krishna like milking a cow, killing Putana, affair with Radha, Kaliya daman etc. all were represented in Kalighat repertoire.

In the village, unrolling the sequential frames of pictures of two great epics while chanting the story was all the part of the traditional performances of patuas in Bengal and Kalighat paintings were no exception to potray the episodes of two great epics. The Kalighat patuas painted stories from the Ramayana and the Mahabharata in a quite fashionable way. The interesting thing in Kalighat painting was the presence of Islamic icons. A N Sarkar and C Mackay described that "It is important to note the presence of strong images from Islam and Christanity in the Kalighat repertoire. The painters sought to capture all slices of the truly cosmopolitan market available to them". One famous representation in Kalighat Paintings was "Duldul Horse" on which Husain, the younger grandson of Prophet Muhammad, was killed in the battle of Karbala. There were many such instances which pertained to Islamic mythology. Today they may be used to comment on social and political issues such as the evils of cinema or promotion literary. Their pata painters used colours which is available as plants and minerals to them to make pigments for the paintings. The gum of the Bel (Wood-apple) fruit and the seeds of tamarind fruit acts as a fixative and as a binder. Some of the colours and their sources are; lime powder for white, turmeric for yellow, lamp black or crushed burnt rice for black, pomegranate juice or vermillion paste for red, indigo for blue, broad bean leaves for green. Some artists purchase commercial paints to use in their art works. Similarly, many artist use brushes that they make out of goat and squirrel hair while other purchase readymade brushes. Usually the dark outlines are added at the end of the painting process. Cloths are adhered to the back to strengthen the seams. Often old cotton sarees are used as the backing and the patterns of the fabric add visual depth to the patuas presentation.

There are mainly two categories of pata painting:-

1. Scroll pata. 2. Square pata 
The width of the scroll pata paintings are normally may be from one to two feet, while the length can be up to 25 feet. This can made with many pieces of papers, wet cotton rags are layered and pasted into cloths grounded with tamarind glue. And the sides of the square pata painting is remain plain and unpainted. There are some examples of Bengal pata painting and Kalighat pata painting.

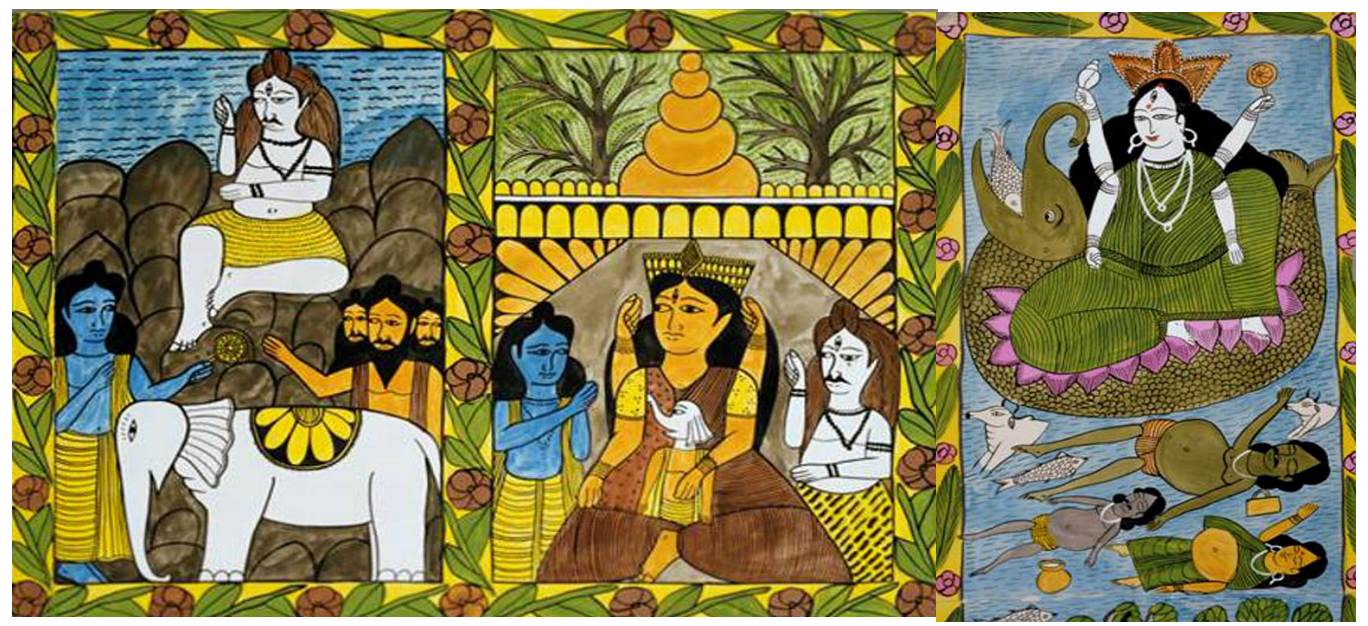

10. Ganesha's life story narrated in Bengal pata scroll painting. Natural colours pigments on paper. Courtesy- Private collection. 11. A story about flood narrated in Bengal pata scroll painting. Natural colour pigments on paper. Courtesy- Private collection

Here is a condensed version of the story of Ganesha: the goddess Parvari was taking bath. She took the skin, she scrubbed from her body and made it into the shape of a boy. Ganesh, to whom she appointed as a guard and placed at the door of the bathroom, at that moment husband of Parvati, god Shiva came at home but Ganesha didn't allow him to enter in the home. Shiva got mad and cut off Ganesh's head. Parvati was upset and told Shiva that he had just killed their son. Shiva vowed to bring back Ganesha's life by replacing his head with the first one he saw on the way, with the help of other god Vishnu and Brahma. Shiva found an elephant, who was the first one he saw, whose head was transplanted into Ganesha's body and Ganesh was brought back his life. This is how the lord Ganesha got his elephant head. (See fig. 10)

The second story is based on a terrible flood, which happened many years ago in Midnapur, West Bengal. The mother Ganges, goddess of secret Ganges River was very angry. She released the water of the river on an area called Midnapur in West Bengal. There was a terrible flood; goat's, buffaloes, cows, trees, all kind fishes and even people began to float away. People finally arrived in boats and helicopters came to help them and provided medicine and food. Finally the water resides and lives are continued. (See fig. 11)

\section{Conclusion}

Today the practice of Kalighat Scroll paintings are no more exist but the tradition of Chinese Scroll Painting and Bengal Pata painting still continues in the villages of different province of China and Bengal where the rich culture are proudly being carried out by the artist, artisans and the patuas which are being handed down through the generations. This is surely a matter of great appreciation and a consortium is needed whose un-tired effort will revive the glorious past of Bengal and Far East.

Funding: The Paper had not got any fund for the publication. 
97 | The Chitrolekha Journal on Art and Design, Vol. 2, No. 3, 2018

\section{References}

Desai, D. (2013). (ed.), Art and Icons: Essays on Early Indian Art. Aryan Books International. Mumbai.

Francaise, A. (1989). \& The Craft Council of West Bengal Calcutta. Patua art: Development of the Scroll Paintings of Bengal Commemorating the Bicentenary of the French Revolution. Peerless. the Radiant Process Private Limited. Calcutta.

Gupta, S.D. (2011). "Village of Painters: a Visit to Naya, Pingla”. Chitrolekha International Magazine in Art and Design. (ISSN- 2231-4822). vol. - 1. No. 3. Calcutta.

Jain, J. (1999). Kalighat Painting: Images from a Changing World. Mapin Publication Pvt. Ltd. Ahmadabad.

Korom, F. J. (2006). Village of Painters: Narrative Scrolls from West Bengal. Museum of New Mexico Press.

Ranjan, A. (2007). and M. P. Ranjan (ed.), Handmade in India/ Crafts of India. National Institution of Design (NID). Ahmadabad. Council of Handmade Development Corporation (COHANDS). New Delhi.

Rawson, J. (1992). The British Museum Book of Chinese Art. British Museum Press Ltd. London.

Som, S. (2001). "The Nineteenth Century Art of Bengal- A Reappraisal”. Rudrangshu Mukherjee and Sati Basu (ed.), Art of Bengal: Past and Present- 1850-2000. CIMA Gallery Pvt. Ltd. Kolkata.

Sullivan, M. (1967). The Art of China. University of California Press Ltd. London. England.

Tregear, M. (1978). Chinese Art. Thames and Hudson Ltd. London. 